\title{
An Unexpected Emergency Room Visit: Penile Strangulation with Rubber Band
}

\section{Acil Servise Beklenmedik Bir Başvuru: Lastik Bant ile Penil Strangülasyon}

\author{
Yurdagul Cetin $\operatorname{Seker}^{1} \mathbb{D}, \operatorname{Emel~Sam}^{2}$ (D, Emre $\operatorname{Sam}^{3} \mathbb{D}$, Fatih $_{\operatorname{Akkas}^{3}}$ (D) \\ ${ }^{1}$ Department of Emergency Medicine, Mus State Hospital, Mus, Turkey \\ ${ }^{2}$ Department of Emergency Medicine, Regional Training and Research Hospital, Erzurum, Turkey \\ ${ }^{3}$ Department of Urology, Regional Training and Research Hospital, Erzurum, Turkey
}

Cite as: Seker YC, Sam E, Sam E, Akkas F. An unexpected emergency room visit: Penile strangulation with rubber band. Grand J Urol 2021;1(1):39-40.

Submission date: 09 December 2020

Acceptance date: 14 December 2020

Online first: 06 January 2021

Publication date: 20 January 2021

Corresponding Author: Emel Sam / Regional Training and Research Hospital, Department of Emergency Medicine, Erzurum, Turkey dremelakcan@hotmail.com ORCID: 0000-0002-2305-0794

A 74-year-old male patient was admitted to the emergency department reaching a depth of $1 \mathrm{~cm}$ surrounding the penis body, bleeding, and discoloration of the penis skin. It was observed that there were white-yellow rubber bands in the incision area in the examination of the patient (Figure 1). Laboratory examinations revealed no pathology. The patient was consulted at the urology clinic. It was learned that he underwent urethral surgery after trauma and he had continuous urinary incontinence and compressed his penis with these rubber bands to prevent it. $18 \mathrm{Fr}$ urethral Foley catheter was inserted. It was observed in the exploration that the rubber bands lasered the penis skin laterally and dorsally to tunica albuginea, and ventrally to corpus spongiosum and urethra level. Five rubber bands were cut and removed (Figure 2). It was observed that corpus spongiosum-urethra and corpus cavernosa were intact in exploration. The penile skin was left for secondary healing after

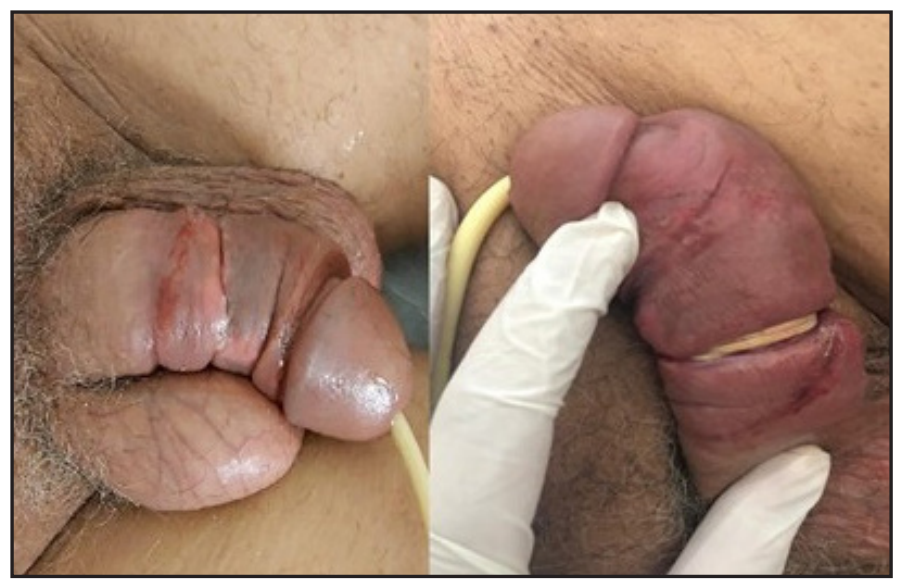

Figure 1. Preoperative appearance

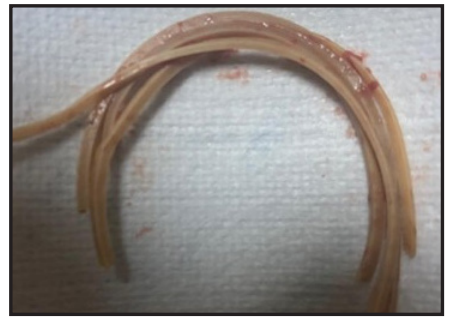

Figure 2. Removed rubber bands

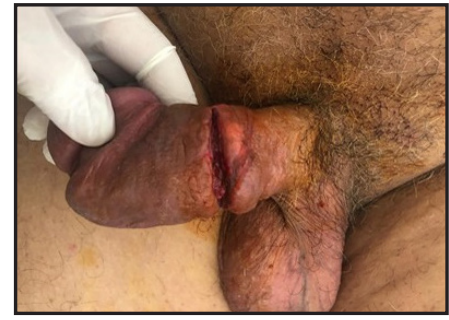

Figure 3. Postoperative appearance sterile cleansing of the skin and subcutaneous tissue (Figure 3). Penis was wrapped with a Coban bandage after the medical dressing. The urethral catheter was removed on the first day after the operation. The patient was prescribed broad-spectrum antibiotherapy, analgesic, anti-inflammatory, and duloxetine for continence. Kegel exercises were practically explained. The patient was referred to the psychiatric clinic before discharge. It was observed in the follow-up one week later that the penis healing was good except for mild edema and the wound healed completely (Figure 4). The penis was found to be completely normal except for skin pigment change in several areas a month later (Figure 5). The patient stated that there was intermittent continence. Written informed consent form was obtained from the patient.

Penile strangulation with a foreign material is a rare condition and was first reported by Gauthier in 1755 . To date, only a few case series have been published in the literature with fewer than 100 case reports. Penile strangulation is a condition that needs to be intervened urgently, and it can lead to complications such as gangrene and amputation of the penis if not treated as soon as possible $[1,2]$.
ORCID: Y.C. Seker 0000-0002-3809-9398

E. Sam $0000-0001-7706-465 X$

\section{F. Akkas 0000-0002-4560-7426}

(C) Copyright 2021 by GJU. This journal is published by Logos Medical Publishing. This is an Open Access article distributed under the terms of the Creative Commons Attribution NonCommercial License (http://creativecommons.org/licenses/by-nc/4.0) which permits unrestricted non-commercial re-use, distribution, and reproduction in any medium, provided the original work is properly cited. 


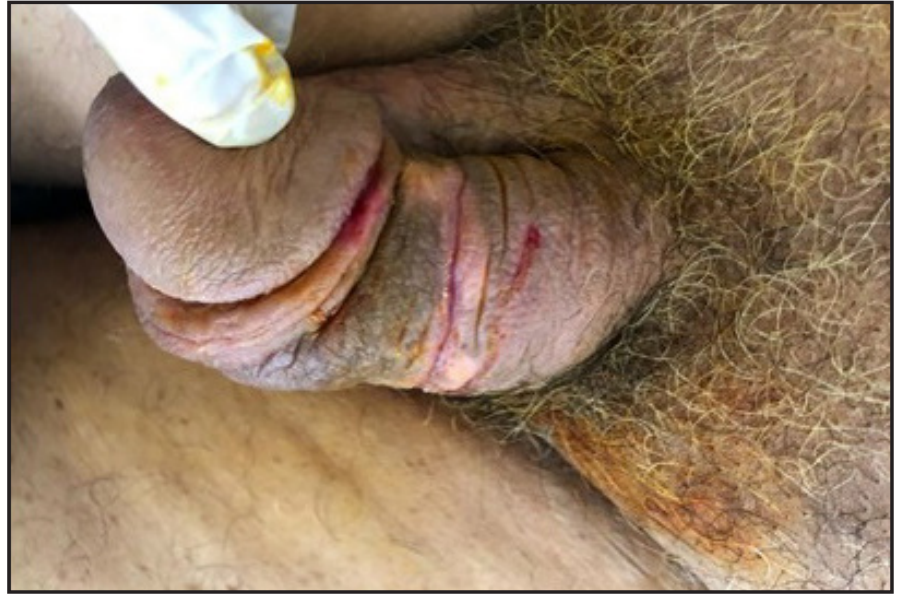

Figure 4. Control appearance after 1 week

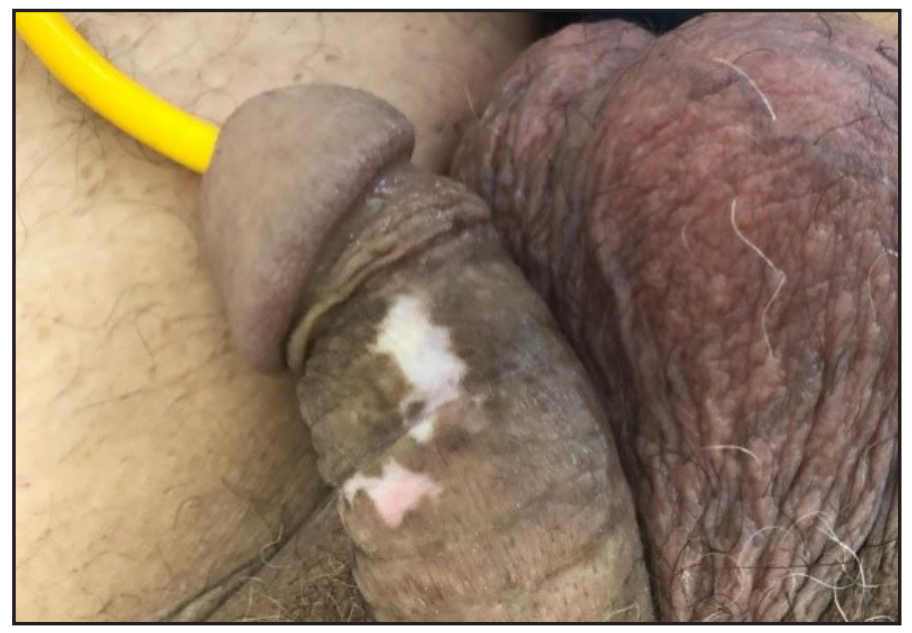

Figure 5. Control appearance after 1 month

Foreign materials used for strangulation can be classified as soft and hard. In the literature, the most common hard materials for strangulation were metallic rings (49.0\%), metallic tubes $(14.8 \%)$, plastic bottles $(12.1 \%)$, rings $(9.4 \%)$ and plastic products $(6.7 \%)$ and the most common soft materials for strangulation were rubber bands $(67.9 \%)$, rubber strings $(13.2 \%)$, threads $(13.2 \%)$ and vinyl products $(1.9 \%)$. The most common causes to use foreign material for penile strangulation were pranks, sexual intercourses, treatments of incontinence, and treatments of phimosis [3].

Complications related to penile strangulation injuries are skin erosion, laceration, infection, urethral transection, penile gangrene, and autoamputation [4]. Bhat et al. developed a grading system for penile strangulation injuries due to constructive objects around the penis and divided them into five categories from penis edema to gangrene. Grade I causes edema only, whereas Grade II involves penile paresthesia. Grade III includes skin and urethral damage but does not include urethral fistula. Grade IV includes the urethral fistula. It involves Grade $\mathrm{V}$ injury, gangrene, necrosis, or complete amputation [5].

The management of the patients is different according to the type of foreign body and the clinical findings of each case. There is not a standard surgical approach [6]. The treatment mainly aims to remove the constricting object as soon as possible to restore venous and lymphatic drainage and arterial flow by preserving the anatomy and functionality of the organ [7]. Thin non-metallic constricting objects are easy to remove in the treatment of penile strangulation. Successful results can be obtained by cutting such objects with simple surgical scissors or a scalpel. Orthopedic surgical instruments or non-medical instruments may be needed in metal objects or in patients with severe edema after penile strangulation [8]. In addition, psychological and psychosexual evaluation of these patients is a part of the treatment.

Keywords: penile strangulation, rubber band, urologic emergency

Ethics Committee Approval: N / A.

Informed Consent: An informed consent was obtained from the patient.

Publication: The results of the study were not published in full or in part in form of abstracts.

Peer-review: Externally peer-reviewed.

Conflict of Interest: The authors declare that they have no conflict of interest.

Financial Disclosure: The authors declare that this study received no financial support.

\section{References}

[1] Maruschke M, Seiter H. Total infarction of the penis caused by entrapment in a plastic bottle. Der Urol Ausgabe A 2004;43:843-4. https://doi.org/10.1007/s00120-004-0623-5.

[2] Noh J, Kang TW, Heo T, Kwon DD, Park K, Ryu SB. Penile strangulation treated with the modified string method. Urology 2004;64:591. https://doi.org/10.1016/j.urology.2004.04.058.

[3] Yoshida T, Watanabe D, Minowa T, Yamashita A, Miura $\mathrm{K}$, Mizushima A. Penile strangulation intentionally using a rubber band to prevent the development of penile cancer. Urol Case Reports 2019;27.

https://doi.org/10.1016/j.eucr.2019.101003.

[4] Badawy H, Soliman A, Ouf A, Hammad A, Orabi S, Hanno A. Progressive hair coil penile tourniquet syndrome: Multicenter experience with 25 cases. J Pediatr Surg 2010;45:1514-8.

https://doi.org/10.1016/j.jpedsurg.2009.11.008.

[5] Bhat AL, Kumar A, Mathur SC, Gangwal KC. Penile Strangulation. Br J Urol 1991;68:618-21.

https://doi.org/10.1111/j.1464-410X.1991.tb15426.x.

[6] Ivanovski O, Stankov O, Kuzmanoski M, Saidi S, Banev S, Filipovski V, et al. Penile strangulation: Two case reports and review of the literature. J Sex Med 2007;4:1775-80. https://doi.org/10.1111/j.1743-6109.2007.00601.x.

[7] Pannek J, Martin W. Penile entrapment in a plastic bottle. J Urol 2003;170:2385.

https://doi.org/10.1097/01.ju.0000095242.41852.83.

[8] Tavukçu HH, Bozkurt İH, Tinay İ, Akbal C. A Rare Urologic Emergency of Penile Strangulation with a Metallic Ring. J Urol Surg 2017;4:32-4.

https://doi.org/10.4274/jus.627. 